\title{
Characterization of a Cucumber Mosaic Virus Isolate and Satellite RNA from the Ornamental Host Ajuga reptans 'Royalty'
}

\author{
J.R. Fisher and S.G.P. Nameth ${ }^{1}$ \\ Department of Plant Pathology, The Ohio State University, Columbus, OH 43210
}

AdDitional INDEX wORDS. virus purification, DNA sequencing, double-stranded RNA

\begin{abstract}
Cucumber mosaic virus (CMV) was isolated from the perennial ornamental mint, Ajuga reptans L. 'Royalty', using melon aphids (Aphis gossypii Glover). The isolate and its associated satellite RNA (satRNA) were biologically and chemically characterized. The satRNA was cloned and sequenced and is 338 nucleotides long and does not induce lethal necrosis on 'Rutgers' tomato (Lycopersicon esculentum Mill.) or severe chlorosis on tobacco (Nicotiana L. spp.). The virus is $\approx 28$ to $30 \mathrm{~nm}$ in diameter and reacts to $\mathrm{CMV}$ serological subgroup I antibodies. The virus is able to infect 'Black Beauty' squash (Cucurbita pepo L.), cucumber (Cucumis sativus L.), and 'Howden' pumpkin (Cucurbita pepo) but is not able to infect green bean (Phaseolus vulgaris L.) or cowpea [Vigna unguiculata (L.) Walp. ssp. unguiculata]. The virus is able to efficiently replicate its satRNA in tobacco and 'Black Beauty' squash but replication is less efficient in cucumber, based on accumulation of double-stranded satRNA.
\end{abstract}

Ajuga reptans is a perennial ornamental mint grown commonly for its foliage in borders or as a groundcover. Cucumber mosaic virus (CMV, genus Cucumovirus), alfalfa mosaic virus (AMV), tobacco streak virus (TSV, genus Ilarvirus), and broad bean wilt virus (BBWV, genus Fabavirus) were reported in this host in Australia(Shukla and Gough, 1983), CMV inDenmark(Kristensen, 1956), and AMV in the United States (Schroeder and Provvidenti, 1972).

CMV is the type member of the cucumovirus group of plant viruses, which includes tomato aspermy (TAV) and peanut stunt viruses (Francki et al., 1979). It is distributed worldwide, has a very wide host range, and is transmitted mechanically, through seed, and by $>60$ aphid species in a nonpersistent manner (Francki et al., 1979). CMV particles are spherical, 28 to $30 \mathrm{~nm}$ in diameter, and encapsidate four functional segments of single-stranded RNA (Francki, 1985; Francki et al., 1979).

Satellite RNAs (satRNAs) are nucleic acids that are dependent on a helper virus for replication and encapsidation, and CMV satRNAs lack significant nucleotide sequence identity to the helper virus genome (Collmer and Howell, 1992; Diaz-Ruiz and Kaper, 1977). SatRNAs may influence the symptoms induced by the helper virus alone. This influence can range from symptom amelioration to symptom exacerbation, and even induction of new symptoms not associated with the helper virus alone (Collmer and Howell, 1992).

Recently CMV, AMV, and TSV were reported in A. reptans cultivars in the United States, and a satRNA was found to be associated with CMV-infected A. reptans 'Royalty' (Fisher and Nameth, 2000). In this paper we report characterization of a CMV isolate and its associated satRNA, including the satRNA nucleotide sequence, from A. reptans 'Royalty' (CMV-'Royalty').

\section{Materials and Methods}

APHID TRANSMISSION. Melon aphids (Aphis gossypii L.) were used to isolate CMV from A. reptans 'Royalty' and transmit the

Received for publication 22 Jan. 2002. Accepted for publication 1 Nov. 2002. Melon aphids were provided by Karen Magnuson and Celeste Welty, Dept. of Entomology, The Ohio State Univ., Columbus. 'Peto 696' tomato seedlings were provided by R.M. Riedel, Dept. of Plant Pathology, The Ohio State Univ., Columbus. Lypholized tobacco tissue containing CMV-fny was provided by Keith Perry, Purdue Univ., West Lafayette, Ind. We also thank Doris Majerczak for technical advice. 'Corresponding author; e-mail nameth.2@osu.edu. virus to tobacco (Nicotiana spp.). A colony of melon aphids was maintained on 'Howden' pumpkin (Cucurbita pepo) leaves. Three groups of 25 aphids each were placed in petri plates containing moist filter paper. The aphids were starved for $3 \mathrm{~h}$ before a $1 \mathrm{~min}$ acquisition feeding period on an A. reptans 'Royalty' leaf and then transferred to 3-week-old Nicotiana tabacum L. 'Glurk', $N$. benthamiana L., $N$. rustica L., and $N$. clevelandii L. seedlings. Three pots of each species containing three seedlings each were inoculated with at least two to three aphids per seedling. One pot of each species was mock-inoculated with aphids that were starved but not acquisition fed. About $30 \mathrm{~d}$ after inoculation, seedlings were transplanted into individual pots and observed over the next several months under greenhouse conditions. Direct antibody-sandwich enzyme-linked immunosorbent assay (DAS-ELISA) was used to test the plants for CMV, AMV, TSV, and TAV (see below). The aphid-transmission experiment was conducted twice and the CMV-'Royalty' isolate was maintained in N. tabacum 'Glurk' and N. rustica.

DAS-ELISA. Samples were tested using a variation of the method described previously (Clark and Adams, 1977). Commercially produced antibodies (Agdia, Inc., Elkhart, Ind.) against CMV, AMV, TSV, and TAV were used. Healthy tissue and extraction buffer alone were used as negative controls. Tissue from an established source known to be infected with the above viruses was used as positive control. Each $100-\mu \mathrm{L}$ sample was dispensed into two test wells (Nunc Maxisorp 96 well polystyrene microtitre plates, Thomas Scientific, Swedesboro, N.J.), and the average absorbance of the two wells at $405 \mathrm{~nm}$ was determined using a microtitre plate reader (EAR 400SF Plus EIA plate reader; SLT Lab Instruments, Hillsboro, N.C.). A sample was considered to be positive if its absorbance was twice the mean of two negative control wells, and a plate was considered valid only if the positive control reacted.

Host RANGE. Nicotiana rustica, N. tabacum 'Glurk' and 'Samsun', cowpea (Vigna unguiculata ssp. unguiculata), green bean (Phaseolus vulgaris), 'Black Beauty' squash (Cucurbita pepo), 'Howden' pumpkin (Cucurbitapepo), cucumber (Cucumis sativis L.) and 'Peto 696', 'Nema 1401', and 'Rutgers' tomato (Lycopersicon esculentum) were used in host range studies. Individual seeds were sown directly into $492-\mathrm{cm}^{3}$ pots containing sterile soilless growing medium (Metro Mix 250; W.R. Grace \& Co., Cambridge, Mass.) and germinated under mist. A set of 
seven pots of each species was planted for each host range study.

Inoculum was prepared by grinding symptomatic $N$. tabacum 'Glurk' tissue infected with the CMV-'Royalty' isolate at a 1:10 ratio in $0.02 \mathrm{M}$ sodium phosphate buffer containing $0.1 \%(\mathrm{w} / \mathrm{v})$ thioglycollic acid ( $\mathrm{pH} 7.0$ ), or in 0.03 m sodium phosphate buffer without thioglycollic acid, and mixed with a small amount of celite $(\approx 1 \% \mathrm{w} / \mathrm{v})$. Squash, pumpkin, cucumber, cowpea, bean, and tomato were inoculated at the cotyledon stage and tobacco was inoculated at the four-true-leaf stage. A set of each species was mock-inoculated with buffer as a negative control. Following inoculation, seedlings were placed in a growth chamber set at $18^{\circ} \mathrm{C}$ with a 12 $\mathrm{h}$ photoperiod, and observed for symptoms over 4 weeks. The host range study was conducted three times and tissue samples from each pot were collected and tested for the presence of CMV by DAS-ELISA. Symptomatic or ELISA-positive samples were also tested for the presence of viral-associated doublestrandedRNA(dsRNA).

LETHAL NECROSIS BIOASSAY. 'Rutgers' tomato seeds were sown directly into $50-\mathrm{cm}^{3}$ cell pack containing Metro Mix 250 and germinated under mist in a greenhouse. Inoculum was prepared as above, and the cotyledons inoculated (White and Kaper, 1987). There were three replications each with 10 plants inoculated with CMV-'Royalty' and one buffer mockinoculation as a negative control. A fourth replication consisted of 55 'Rutgers' seedlings inoculated with CMV'Royalty' and six buffer mock inoculations. Seedlings were grown in a growth chamber under the same conditions as the host range plants, and observed over 4 to 6 weeks. All seedlings were tested for the presence of CMV by DAS-ELISA as described previously.

VIRAL dsRNA ANALYSIS. Viral-associated double-stranded ribonucleic acid (ds-RNA) was extracted and purified as described previously (Jordan et al., 1983; MorrisandDodds, 1979). DsRNA was roysat

dsat

gsat

esat

blsat

b2sat

b3sat

w11sat

wl2sat

ysat

oy2sat

roysat

isat

gsat

esat

b1sat

b2sat

b3sat

wlisat

wl2sat

ysat

oy2sat

roysat

dsat

gsat

esat

blsat

b2sat

b3sat

wl1sat

wl2sat

ysat

oy2sat

roysat

dsat

gsat

esat

blsat

b2sat

b3sat

wllsat

wl2sat

ysat

oy2sat loaded onto $5 \%$ or $10 \%$ polyacrylamide gels and analyzed by electrophoresis. Ethidium bromide-stained dsRNA bands were visualized on a transilluminator $(302 \mathrm{~nm})$ and photographed with Polaroid type 667 black and white film (Polaroid Corp., Waltham, Mass.).

VIRUS PURIFICATION. CMV-'Royalty' and subgroup I strain CMV-Fny were purified from $N$. tabacum 'Glurk' or $N$. rustica using a modification of the protocol of Lot et al. (1972). Following emulsification and clarification, the preparation was subjected twice to differential centrifugation and purified further by ultracentrifugation in $10 \%$ to $40 \%$ sucrose density gradients. The virus was repelleted by ultracentrifugation, resuspended in borate buffer $(5.0$ mM sodium tetraborate, $0.5 \mathrm{~m}$ EDTA, $\mathrm{pH} 9.0$ ), and the preparations used for electron microscopy (EM), sodium dodecyl sulfate poly-
GTTTTGTTTGTTAGAGAACTGCGTAGAGGGGTTGTATCTACGTGAGGATCTGTCACTC-GTTTTGTTTGATGGAGAATTGCGCAGAGGGGTTATATCTGCGTGAGGATCTGTCACTC-GTTTTGTTTGTTAGAGAATTGCGTAGAGGGGTTGTATCTACGTGAGGATCTATCACTC-GTTTTGTTTGATGGAGAACTGCGTGGAGGGGTTGTATCTGCGTGGGGATCTGTCATCTCG GTTTTGTTTGTTAGAGAATTGCGTAGAGGGGTTATATCTACGTGAGGATCTATCACTC-GTTTTGTTTGTTAGAGAATTGCGTAGAGGGGTTATATCTATGTGAGGATCTATCACTC-GTTTTGTTTGTTAGAGAATTGCGTAGAGGGGTTATATCTATGTGAGGATCTATCACTC-GTTTTGTTTGATGGAGAATTGCGTAGAGGGGTTATATCTACGTGAGGATCCGTCACTC-GTTTTGTTTGATGGAGAATTGCGTAGAGGGGTTATATCTACGTGAGGATCTATCACTC-GTTTTGTTTGATGGAGAATTGCGTAGAGGGGTTATATCTGCGTGAGGATCCATCACTC-GTTTTGTTTGTTGGAGACCCGCGCGGAGGGGATATATTCGTGCGGTGATCCTTCACTC--

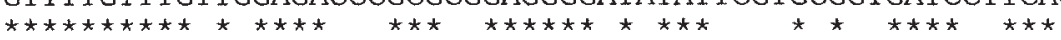

GGCGGTGTGGGTTACCTCCCTGCTACGGCGGGTTGAGT--.---TGACG-CACCTCGGA GGCGGTGTGGGATACCTCCCTGCTAAGGCGGGTTGAG-------TGATGTTCCCTCGGA GGCGGTGTGGGTTACCTCCCTGCTACGGCGGGTTGAG_-...-..TGACG-CACCTCGGA GGCGGTGTGGGATACCTCCCTGCTAAGGCGGGTTGAGA-_..-_-TGACG-TATCTCGGA GGCGGTGTGGGATACCTCCCTGCTAAGGCGGGTTGAG-_-_-_-TGACG-CACCTCGGA GGCGGTGTGGGATACCTCCCTGCTACGGCGGGATGAG--------TGACG-CACCTCGGA GGCGGTGTGGGATACCTCCCTGCTACGGCGGGATGAG-_-_---TGACG-CACCTCGGA GGCGGTGTGGGTTACCTCCCTGCTACGGCGGGTTGAGT--_-_-TGACG-CACCTCGGA GGCGGTGTGGGATACCTCCCTGCTAAGGCGGGTTGAGT------TGACGGCACCTCGGA GGCGGTGTGGGATACCTCCCTGCTAAGGCGGGTTGAG--.----AGTG-TATCTCGGA GGCGGTGTGGGTTAACTCCCTGCTAAGGCGGGTTGGAGACTGCGCCCGAGACAGGCCGGA

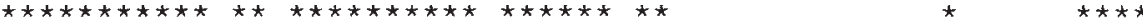
127 148|| 149

CT-_-GGGGACCGCT-GGCTTGCGAGCTATGTCCGCTACTC_-_._._. CT---GGGGACCGCT-GGCTTGCGAGCTATGTCCGCTACTC-_............ CT---GGGGACCGCT-GGC---CGAGCTATGTC-GCTACTC-_-_._. CT---GGGGACCGCT-GGCTTGCGAGCTATGTCCGCTACTC-_............ CT---GGGGACCGCT-GACTTGCGAGCTATGTC-GCTGTTC_.............. CT---GGGGACCGCT-GACTTGCGAGCTATGTCCGCTGCTC-............ CT-_-GGGGACCGCT-GACTTGCGAGCTATGTCCGCTGTTC-_-_._. CTC-_GGGGACCGCTTGGTTTGCGAGTATCGTCCGC-ATTC_.............. CT-_-GGGGACCGCT-GACTTGCGAGTATCGTCCGCTGCTC-_-_..........CTG--GAGGCGGGATGTCTGCGGGTGTTCCGTCTGCTGCCCACGATGGTGGGAGCCACCC CCTTGGGGGAGCCCACGAGCCGCGTGGGAACGTAGCGGTTTCCGGTTGAACTGGCGCCGG * * * * * * * *

1531

-.........-. TAGCACTACGCA-.-CTCATTTGAGCCCCCGC-TCAGTTTGCTA - . - - T-CAGTACTACACT---CTCATTTGAGCCCCCGC-TCAGTTTGCTA - - - - T-CAGCACTACGCA---CTCAATTGAGCCCCCGC-TCAGTTCGCTA ---------- T-CAGCACTACGCA----CTCAATTGAGCCCCCGC-TCAGTTCGCTA _... TTCAGCACCACGCA-_- CTCATTTGAGCCCCCGC-TCAGTTCGCTA -....... TTCAGCACCACGCA - - CTCATTTGAGCCCCCGC-TTAGTTCGCCA -..... TTTAGCACTACGCG---CCAATTTGAGCCCCCGC-CTAGTTTGCCA - - - - - TTCAGCACPACGCA----TCAATTTGAGCCCCCGCCTCAGTTTGCTA CAGGGGCGACTTTTTCAGCTCTGCATTT---CTCATTTGAGCCCCCGC-TCAGTTTGCTA AGGCCTCCAGCGGCCTGTTTCGCCGCTTCCCTCCATTTGAGCCCCCGC-CCAGTTTGCTA 
acrylamide gel electrophoresis (SDS-PAGE), and western blot analysis.

Transmission electron MiCroscopy. A 5- $\mu \mathrm{L}$ drop of purified virus preparation was pipetted onto a Formvar-coated copper EM grid and incubated for 1 to $2 \mathrm{~min}$ at room temperature $\left(25^{\circ} \mathrm{C}\right)$. The virus was then drawn off with filter paper and the preparation negatively stained with $5 \mu \mathrm{L}$ uranyl acetate $(2 \% \mathrm{w} / \mathrm{v})$ for $1 \mathrm{~min}$. The virus was observed using a transmission electron microscope [model EM 300 (60 kV); Philips Electronics Instruments; Wilmington, N.J.]. CMV-'Royalty' particle size was determined using an American Type Culture Collection (Rockville, Md.) tobacco mosaic virus (TMV) particle reference (Zaitlin and Israel, 1975).

Protein analysis. Purified virus was denatured as described previously (Sambrook et al., 1989). Denatured protein samples (5 to $20 \mu \mathrm{L}$ ) were loaded on discontinuous SDS-polyacrylamide mini gels (5\% stacking/10\% resolving) and electrophoresed at 100 to 125 $\mathrm{V}$ for 1 to $2 \mathrm{~h}$. The gels were stained with coomassie brilliant blue for 1 to $4 \mathrm{~h}$, destained overnight, and mounted in a gel-drying frame (Biodesigns, Inc., of New York, Carmel) between two cellophane sheets as per the manufacturer's instructions.

Western transfer AND IMMUNOLOGICAL DETECTION. Protein samples were denatured and electrophoresed on discontinuous SDS-polyacrylamide gels as above. The proteins were electroblotted onto a piece of $0.2 \mu \mathrm{m}$ nitrocellulose membrane using standard procedures (Sambrook et al., 1989). The membranes were blocked, incubated for $2 \mathrm{~h}$ at $25^{\circ} \mathrm{C}$ with mouse anti-CMV subgroup I or subgroup II monoclonal antibodies (Agdia, Inc.) and then $1 \mathrm{~h}$ at 25 ${ }^{\circ} \mathrm{C}$ in rabbit anti-mouse alkaline phosphatase-conjugated antibodies. Protein bands were detected in alkaline phosphatase substrate solution using standard procedures (Sambrook et al., 1989).

Cloning of The CMV-'Royalty' satRNA. CMV-'Royalty' dsRNA was purified from $N$. tabacum 'Glurk' as described above. DsRNA was electrophoresed in a $0.8 \%$ agarose gel for $1 \mathrm{~h}$, the dssatRNA band cut from the gel, and the agarose fragment processed through an agarose spin-through column (Supelco, Inc.). The concentration of the band-isolated dssatRNA was estimated visually by electrophoresis in a $0.8 \%$ agarose gel. First and second strand synthesis were performed using the Choice System for cDNA Synthesis reagent kit (Life Technologies, Inc., Gaithersburg, Md.) as per the manufacturers instructions. About $675 \mathrm{ng}$ of gel-purified dssatRNA was used as template for first strand synthesis.

Consensus primers were designed by comparing the sequences of G-satRNA, B1-satRNA, B2-satRNA, B3-satRNA, WL1-satRNA, WL2-satRNA(Garcia-Arenal et al., 1987), E-satRNA, OY-satRNA (Hidaka et al., 1988), Y-satRNA (Hidaka et al., 1984), and DsatRNA (Kurath and Palukaitis, 1987). The primer sequences 5'GTTTTGTTTGTTAGA-GAACTG-3', which hybridizes to the 3' endofminus-sensesatRNA, and5'-GGAGATGGTCCTGGG-3', which hybridizes to the 3 ' end of positive-sense satRNA, were used to reverse transcribe cDNAs.

cDNAs were purified from primers, nucleotides, and enzyme using the QIAquick PCR purification kit (QiaGen, Inc., Santa Clarita, Calif.). pBluescript SK (Strata-gene, LaJolla, Calif.) DNA was isolated from Eschericia coli Migula and digested with SmaI restriction endonuclease for blunt end ligation, and quantified at 260. The plasmid was not dephosphorylated before ligation.

Insert DNA was mixed with plasmid DNA at a molar ratio of 1:1. Ligations, including controls using only plasmid DNA digested with SmaI, were carried out using standard procedures (Sambrook et al., 1989). The T4 ligase was not heat-inactivated following the reactionincubation, and the ligation reaction products were used directly to transform competent E. coliDH5 cells (Sambrooketal., 1989). Putative transformant colonies were evaluated using a standard small scale plasmid isolation procedure (Sambrook et al., 1989). Plasmid DNA was digested with HindIII and $\mathrm{XbaI}$ restriction endonucleases and the minipreps evaluated on $1 \%$ agarose gels. Clones with inserts similar in size to an (S)CARNA5 (ATCC 45124) cDNA were prepared for sequencing using the Promega WizardPlus Mini Prep DNA Purification kit (Promega Corp., Madison, Wis.), 
and the DNA purity and quantity assessed spectrophotometrically at $\mathrm{A}_{260 / 280}$. Clones were sequenced by the DNA Sequencing Facility, The Ohio State University, Columbus, and CLUSTAL$\mathrm{W}$ (version 1.4), and DNA Strider version $1.3 \mathrm{f} 3$ used to do multiple sequence alignments and pairwise alignments, respectively.

Southern hybridization. A digoxigenin (DIG) labeled (S)CARNA-5 (ATCC 45124) cDNA probe was prepared (Genius II DIG-DNA Labeling Kit, Boehringer-Mannheim Biochemical, Indianapolis, Ind.). Putative satRNA cDNA clones were screened by hybridization to the DIG-labeled cDNA. Following electrophoresis in $1 \%$ or $1.5 \%$ agarose gels, cDNA inserts that had been excised from plasmids were chemically denatured, blotted onto nylon membrane, and hybridized to the probe. Southern blot hybridization was performed at $68{ }^{\circ} \mathrm{C}$ and high stringency washes performed at $68{ }^{\circ} \mathrm{C}$ in $0.1 \times \mathrm{SSC}$ buffer (Sambrook et al., 1989).

\section{Results and Discussion}

CMV-'Royalty' Satellite RNA. Seventy-four colonies were screened for inserts similar in size to (S)CARNA-5 and 43 of those sequenced. Both strands of the clones were sequenced, CLUSTAL-W (version 1.4) was used to align the clone sequences, and a 338 base sequence was obtained (Fig. 1). CLUSTAL-W was also used to align the 'Royalty' satRNA sequence with the 10 satRNA sequences used to design the cloning primers (Fig. 1), and DNA Strider was used to make pairwise alignments and comparisons of the Royalty satRNA sequence with those 10 satRNA sequences. The percentage identity of the CMV-'Royalty' satRNA sequence to those 10 satRNAs is presented in Table 1. A BLASTN (gapped BLASTN with Repeat Masker; Baylor College of Medicine website) search of the DNA database was performed to locate other CMV satRNA sequences with higher percentage identity to 'Royalty' satRNA. These results are shown in Table 1.

Disease phenotype sequence domains and key nucleotide positions have been identified in CMV-satRNAs. A nucleotide change at position 149 from $U$ to $C$ alters host specificity of the chlorosis phenotype from tomato to tobacco (Sleat and Palukaitis, 1992). Other nucleotide positions important in the chlorosis phenotype are 127: $\mathrm{G}$ in nonchlorosis inducing satRNAs and A in chlorosis-inducing satRNAs; 148: $\mathrm{G}$ in chlorosis-inducing satRNAs and A in nonchlorosis-inducing satRNAs; and 153: U in all chlorosis-inducing satRNAs and deleted in all others (Sleat and Palukaitis, 1992). The nucleotides at these positions in the CMV-'Royalty' satRNA clones are G (127), A (148), C (149), and a deletion at position 153 (Fig. 1), and are conserved among all the clones, suggesting the nonchlorosis-inducing phenotype. The 5' 223 bases of necrogenic satRNA variants are identical but nonnecrogenic satRNA variants have at least nine variable regions, five of which are in the 5' two-thirds of the molecule (Kaper et al., 1988). The CMV-'Royalty' satRNA differs from the necrogenic D-satRNA in 14 nucleotide positions in the 5' 220 bases of the molecule (Fig. 1). Necrogenic satRNAs also have a three-base deletion relative to their non-necrogenic counterparts. In D-satRNA this deletion is between nucleotides 300 to 302 (Sleat and Palukaitis, 1990), and is not present in the CMV'Royalty' satRNA (Fig. 1). The greatest number of nucleotide differences between necrogenic and ameliorative satRNAs is

Table 1. Comparison of percentage identity between the CMV-'Royalty' satRNA (roysat) nucleotide sequence, 10 previously published satRNA sequences, and the 11 satRNA sequences obtained from a BLASTN database search.

\begin{tabular}{|c|c|c|c|c|}
\hline $\begin{array}{l}\text { Satellite RNA/ } \\
\text { (accession no.) }\end{array}$ & $\begin{array}{c}\text { No. of } \\
\text { nucleotides }\end{array}$ & $\begin{array}{c}\text { No. of conserved } \\
\text { nucleotide positions }\end{array}$ & $\begin{array}{l}\text { Identity with CMV } \\
\text { 'Royalty' satRNA }\end{array}$ & $\begin{array}{l}\text { Necrogenic } \\
\text { phenotype }^{\mathrm{x}}\end{array}$ \\
\hline Royalty satRNA & 338 & $\mathrm{NA}^{\mathrm{w}}$ & 100 & - \\
\hline g satRNA (m16585) & 333 & $314 / 338$ & 92.9 & - \\
\hline e satRNA (m20844) & 341 & $312 / 341$ & 91.5 & - \\
\hline b1 satRNA (m16586) & 336 & $308 / 338$ & 91.1 & - \\
\hline b2 satRNA (m16587) & 339 & $309 / 340$ & 90.9 & - \\
\hline b3 satRNA (m16588) & 337 & $310 / 339$ & 90.5 & - \\
\hline w12 satRNA (m16590) & 340 & $303 / 341$ & 88.9 & - \\
\hline w11 satRNA & 336 & $294 / 341$ & 86.2 & - \\
\hline d satRNA & 335 & $292 / 338$ & 86.4 & + \\
\hline y satRNA & 368 & $289 / 373$ & 77.5 & + \\
\hline oy satRNA & 386 & $280 / 389$ & 72.0 & - \\
\hline (z75876) & 339 & $321 / 339$ & 94.7 & \\
\hline (z75871) & 339 & $320 / 339$ & 94.4 & \\
\hline (z75870) & 340 & $321 / 340$ & 94.4 & \\
\hline (z75882) & 339 & $319 / 339$ & 94.1 & \\
\hline (j02060) & 336 & $318 / 338$ & 94.1 & - \\
\hline (z75872) & 339 & $319 / 340$ & 93.8 & \\
\hline (z75873) & 339 & $319 / 339$ & 93.8 & \\
\hline (x86408) & 340 & $317 / 341$ & 93.0 & \\
\hline (x53534) & 339 & $315 / 339$ & 92.9 & - \\
\hline (x69136) & 339 & $313 / 339$ & 92.3 & - \\
\hline$(\mathrm{m} 14934)$ & 339 & $312 / 339$ & 92.0 & - \\
\hline
\end{tabular}

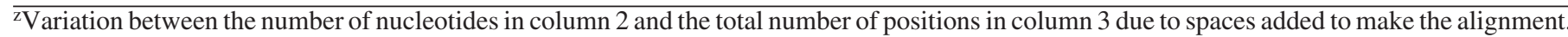
yPercentage of conserved nucleotide positions with 'Royalty' satRNA.

${ }^{\mathrm{x}}$ Satellite RNAs expressing the necrogenic (+) or nonnecrogenic (-) disease phenotype, where known.

${ }^{\mathrm{w}} \mathrm{NA}=$ not applicable. 
Table 2. Summary of symptoms and ELISA results for host range study.

\begin{tabular}{lcc}
\hline \hline Host & Symptoms & Days postinoculation \\
\hline 'Black Beauty' squash & Chlorotic spots/veinal chlorosis & 7 \\
Cucumber & Chlorotic spots/veinal chlorosis & $10-12$ \\
'Howden' pumpkin & Chlorotic spots/veinal chlorosis & $13-14$ \\
Cowpea & None & -- \\
Green bean & None & -- \\
'Peto 696' tomato & None & -- \\
'Nema 1401' tomato & None & -- \\
'Rutgers' tomato & None or mild mosaic & 45 \\
\hline
\end{tabular}

${ }^{\mathrm{z}}$ Results of DAS-ELISA when using CMV antibodies.

located in the $3^{\prime}$ one-third of the molecule between nucleotides 286 to 310 (Sleat and Palukaitis, 1990). There are four regions of variability between nucleotides 280 to 320 in D-satRNA relative to 'Royalty' satRNA (Fig. 1), suggesting 'Royalty' satRNA is a nonnecrogenic satRNA.

Of the 10 published sequences used for primer design, 'Royalty' satRNA has the highest percentage identity to E-satRNA (92.9\%), G-satRNA (91.5\%), B1-satRNA $(91.1 \%)$ and B2satRNA (90.9\%) (Table 1), all ameliorative satRNAs (GarciaArenal et al., 1987; Hidaka et al., 1988), and only $86.4 \%$ identity with the necrogenic D-satRNA (Table 1).

LETHAL NECROSIS BIOASSAY. Six of thirty 'Rutgers' tomato plants tested were positive for CMV by DAS-ELISA. All six of the plants appeared initially asymptomatic. After $\approx 45 \mathrm{~d}$ one plant developed a very mild mosaic symptom, and was slightly paler in color than the controls. After $\approx 50$ to $52 \mathrm{~d}$ the new leaflets on this plant began to show slight distortion. The other five plants remained symptomless. Forty-eight of the fifty-five plants in the fourth replication tested positive for CMV by DAS-ELISA. One plant showed a slight leaf distortion similar to that seen on the plant from the first replication. All others were asymptomatic. It has been reported that contamination of a nonnecrogenic satRNA isolate with as little as $0.5 \%$ of a necrogenic satRNA can cause tomato necrosis death of $100 \%$ of the test plants (Kaper et al., 1988), and there was no evidence of lethal necrosis in any of the 'Rutgers' tomato plants after $>45 \mathrm{~d}$. These results support the nucleotide sequence data, and demonstrate that 'Royalty' satRNA is nonnecrogenic and ameliorative in nature.

APHID TRANSMISSION AND HOST RANGE. Mild mosaic symptoms appeared on $N$. rustica and $N$. tabacum 'Glurk' $\approx 5$ weeks after aphid inoculation. The symptoms developed into severe mosaic and leaf puckering on younger $N$. rustica leaves, and vein clearing and mild mosaic on younger N. tabacum 'Glurk' leaves. Nicotiana benthamiana seedlings were stunted compared to the mockinoculated controls, but showed no other symptoms, and no symptoms developed on $N$. clevelandii seedlings. CMV was detected in all three $N$. rustica samples, and two of three $N$. tabacum 'Glurk' samples, but was not detected in any of the $N$. clevelandii samples by DAS-ELISA. The $N$. benthamiana plants were too small to test. Once CMV was transmitted to N. tabacum by $A$. gossypii, the virus was then easily mechanically transmissible to tobacco, squash, cucumber, and pumpkin using symptomatic N. tabacum 'Glurk' as inoculum. CMV-'Royalty' induced mild mosaic and mild vein clearing on $N$. tabacum 'Glurk' and 'Samsun', and a very mild mosaic symptom on $N$. clevelandii which disappeared after $28 \mathrm{~d}$. The presence of CMV in mechanically inoculated $N$. clevelandii was confirmed by ELISA and demonstrates that $N$. clevelandii is a host for CMV-'Royalty' even though A. gossypii failed to transmit it to this host. These results also support the nucleotide sequence data, and demonstrate that the 'Royalty' satRNA is nonchlorosis-inducing on tobacco. None of the test plants developed the brilliant chlorosis that has been described for chlorosis-inducing satRNAs (Sleat and Palukaitis, 1992).

Results of the host range study are shown in Table 2. and were similar for all three replications. Symptoms on 'Black Beauty' squash developed the fastest, became progressively more severe over $28 \mathrm{~d}$, but did not kill the plants. Symptoms on cucumber were milder and took longer to develop, and symptoms on 'Howden' pumpkin were even milder. DAS-ELISA results confirmed the presence of CMV.

No local lesions developed on cowpea cotyledons in any of the three host range replications. Some CMV strains such as CMVY infect cowpea systemically (Francki et al., 1979), but ELISA confirmed that there was no systemic infection. Thus, cowpea is neither a local lesion nor systemic host for CMV-'Royalty'. Likewise, no symptoms were observed on green bean or 'Peto 696' or 'Nema 1401' tomato, and ELISA confirmed lack of infection. Certain CMV strains, such as CMV-B, infect Phaseolus L. spp. systemically while others, such as CMV-C, do not (Provvidenti, 1976). CMV-'Royalty' is a strain unable to infect $P$. vulgaris.

VIRAL dsRNA ANALYSIS. DsRNA analysis of selected symptomatic N. tabacum 'Glurk', squash, and cucumber samples from the host range studies revealed a dsRNA banding pattern consistent with that of CMV and an associated satellite RNA in 'Glurk' tobacco, squash, and cucumber (Dodds et al., 1984; Fisher and Nameth, 2000; Valverde et al., 1990). The dssatRNA appeared to accumulate to a higher level in 'Black Beauty' squash than in cucumber (Fig. 2). These results are consistent with reports that satRNA replication in cucurbits is generally poor, while replication in solanaceous hosts, such as tobacco, is more efficient

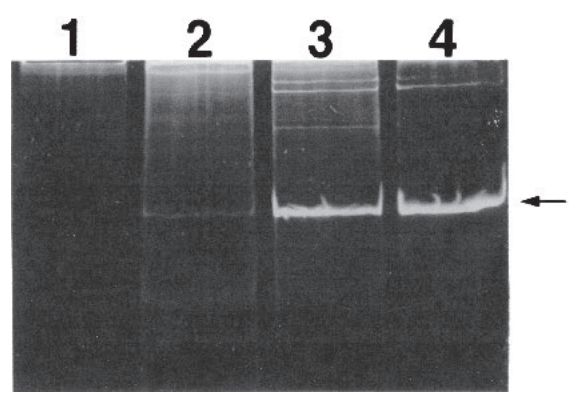

Fig. 2. Ten percent polyacrylamide gel electrophoresis of dsRNA extracted from host range samples. Lane $1=$ asymptomatic 'Peto 696' tomato; lane $2=$ symptomatic cucumber; lane 3 = symptomatic 'Black Beauty'squash; and lane 4 = CMV-'Royalty' isolate in N. tabacum 'Glurk'. Arrow indicates doublestranded satRNA band. 


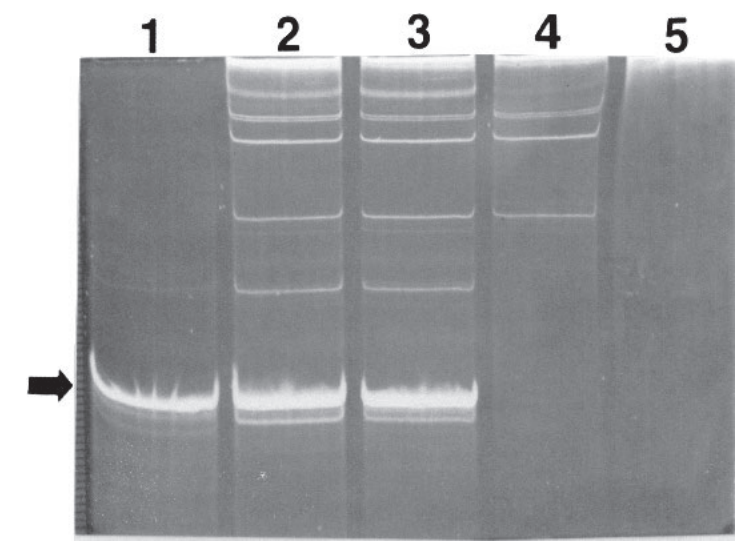

Fig. 3. Five percent polyacrylamide gel electrophoresis of dsRNA extracted from 'Rutgers' tomato positive for CMV-'Royalty' by DAS-ELISA. Lane $1=\mathrm{CMV}$ 'Royalty' isolate in N. tabacum 'Glurk', lanes 2 and $3=$ asymptomatic 'Rutgers' tomato samples, lane 4 = 'Rutgers' tomato sample showing slight leaf distortion, and lane $5=$ healthy 'Rutgers' tissue. Arrow indicates dssatRNA.

(Roossinck et al., 1992). It also has been reported that efficient replication of the WL1 satRNA in 'Black Beauty' squash is helper strain-dependent (Roossinck and Palukaitis, 1991). CMV-Fny replicates the WL1 satRNA efficiently in all hosts, including 'Black Beauty' squash. CMV-Sny, however, is incapable of efficiently replicating the WL1 satRNA in this squash cultivar (Roossinck and Palukaitis, 1991). The dsRNA data indicate that CMV-'Royalty' is capable of efficiently replicating its satRNA in N. tabacum 'Glurk' and 'Black Beauty' squash, but replication is not as efficient in cucumber based on the accumulation of dssatRNA (Fig. 2) when equal gram equivalents of tissue were analyzed. The six 'Rutgers' tomato plants from the lethal necrosis assay were analyzed for the presence of dsRNA and five of the six plants produced dsRNA banding patterns consistent with that reported for CMV and satRNA (Dodds et al., 1984; Valverde et al., 1990). The sixth plant produced a banding pattern that lacked the dssatRNA (Fig. 3). The five plants which produced the dsRNA banding pattern including the dssatRNA were all asymptomatic while the plant that produced the dsRNA banding pattern lacking the dssatRNA showed mild mosaic and slight leaf distortion of the young leaflets. The 48 CMV-positive 'Rutgers' plants from the fourth replication were not tested for dsRNA. It has been proposed that dssatRNA plays a role in the disease modu-

Fig. 4. (A) 10\% SDS-PAGE gel stained with Coomassie brilliant blue. Lanes 1 and $5=$ purified CMV-'Royalty'; lanes 2 and 4 = purified CMVFny; and lane 3 = benchmark protein ladder. Apparent molecular weights of markers are indicated at right in $\mathrm{ku}(\mathrm{u}=$ united atomic mass unit). Arrow next to lane 1 indicates coat protein. (B) Western blot of SDS-PAGE gel in Fig. 4A. Lanes 1 and $5=$ purified CMV-'Royalty'; lanes 2 and $4=$ purified CMV-Fny; lane $3=$ benchmark protein ladder (69 ku marker indicated at right). The left half of the membrane (lanes 1 and 2, and half of 3 ) was treated with CMV subgroup I to lane 1 indicates the coa antibodies, and the right half (half of lane 3, and lanes 4 and 5) was treated with CMV subgroup II antibodies. Arrow next to protein.

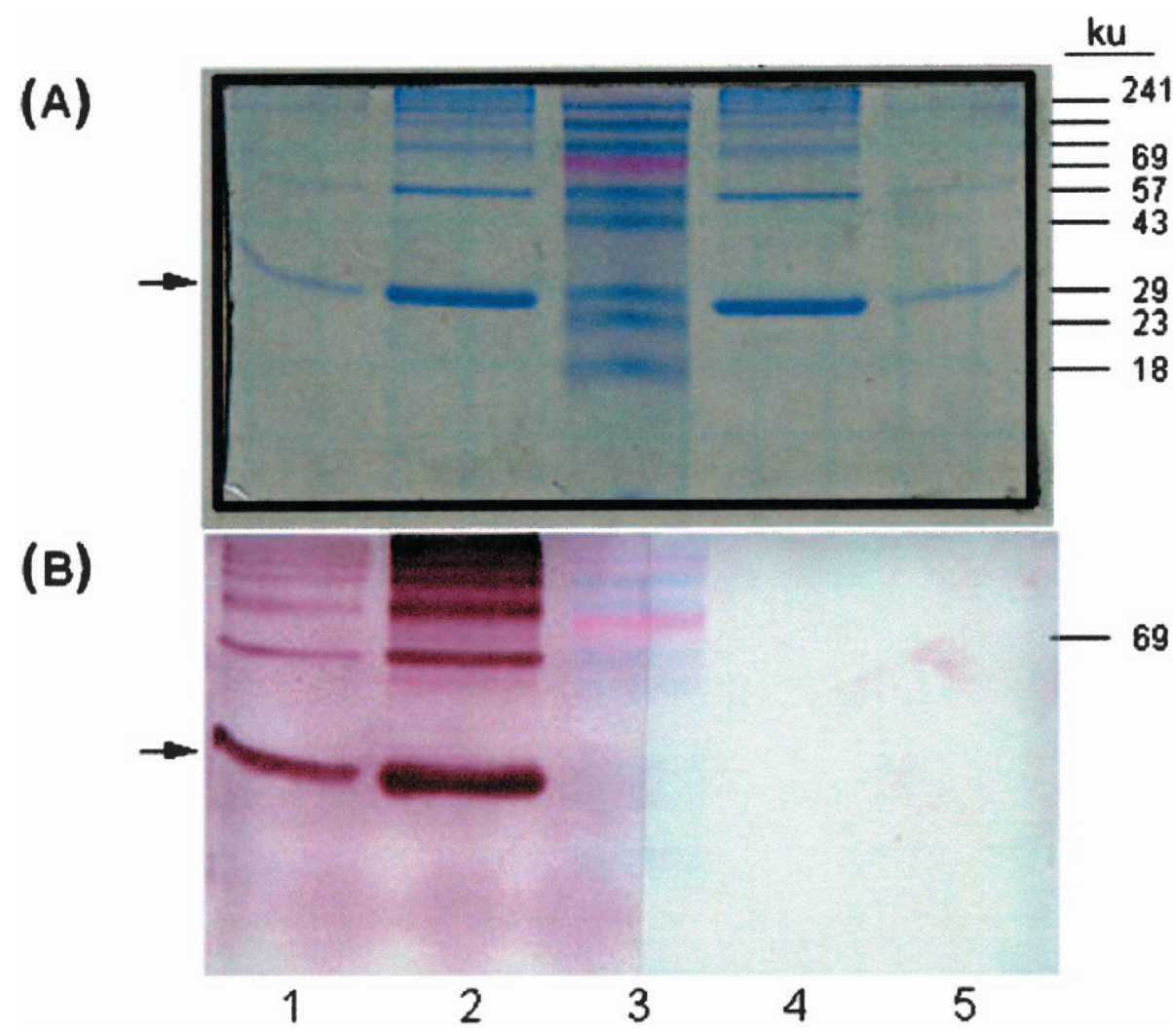

lating effects of satRNAs (Habili and Kaper, 1981). Clearly the dssatRNA was accumulating to high levels in the five 'Rutgers' plants (Fig. 3), and this accumulation correlated with the absence of symptoms. The lack of dssatRNA correlated with mild symptoms.

The VIRUs. Purification of the CMV-'Royalty' isolate from aphid-inoculated $N$. rustica produced a single light-scattering band in $10 \%$ to $40 \%$ sucrose density gradients. Purified CMVFny also produced a single light-scattering band in sucrose gradients. When the two purified preparations were mixed, the particles were indistinguishable under the TEM. CMV-'Royalty' particles were estimated to $b e \approx 27.43 \mathrm{~nm}( \pm 1.53 \mathrm{~nm})$ in diameter, which falls within the 28 to $30 \mathrm{~nm}$ range reported for CMV (Francki et al., 1979).

Purified CMV-'Royalty' and CMV-Fny proteins produced similar banding patterns when subjected to SDS-PAGE (Fig. 4A). A major band corresponding to the coat protein was located between the 23 to $29 \mathrm{ku}$ markers ( $\mathrm{u}=$ unified atomic mass unit) (Fig. 4A). Several higher molecular weight bands were visible in both preparations. CMV-'Royalty' and CMV-Fny proteins both reacted positively with the CMV subgroup I antibodies, but not the subgroup II antibodies (Fig. 4B). Since we lacked a positive control to demonstrate reactivity of the CMV-II antibodies in our western blot, we had tissue samples tested commercially (Agdia, Inc.) against CMV-I and CMV-II. Results confirmed that CMV'Royalty' reacted to CMV-subgroup I antibodies, but not CMVII antibodies. These results indicate that CMV-'Royalty', like CMV-Fny, belongs to the CMV serological subgroup I (Owen and Palukaitis, 1988; Sleat and Palukaitis, 1990a), and is not a mixed population of subgroup I and II strains.

It is important to be aware of $A$. reptans as a potential reservoir for CMV and satRNA since it is a perennial host. Furthermore, even though the 'Royalty'-satRNA appears to have an ameliorative phenotype it has been shown that a single nucleotide change 
can alter the phenotype of an ameliorative satRNA to necrogenic (Sleat and Palukaitis, 1990). Given the potential that RNA viruses have for rapid mutation (Holland et al., 1982; Steinhauer and Holland, 1987) it is important to be aware of the potential threat that a satRNA in a perennial host may pose.

\section{Literature Cited}

Clark, M.F. and A.N. Adams 1977. Chracteristics of the microplate method of enzyme-linked immunosorbent assay for detection of plant viruses. J. Gen. Virol. 34:475-83.

Collmer, C.W. and S.H. Howell. 1992. Role of satellite RNA in the expression of symptoms caused by plant viruses. Annu. Rev. Phytopathol. 30:419-442.

Diaz-Ruiz, J.R. and J.M. Kaper. 1977. Cucumber mosaic virus-associated RNA 5. III. Little nucleotide sequence homology between CARNA 5 and helper RNA. Virology 80:204-213.

Dodds, J.A., T.J. Morris and R.L. Jordan. 1984. Plant viral doublestranded RNA. Annu. Rev. Phytopathol. 22:151-168.

Fisher, J.R. and S.T. Nameth 2000. Virus assessment of Ajuga reptans cultivars reveals alfalfa mosaic, tobacco streak, and cucumber mosaic (CMV) viruses, and a CMV satellite RNA. HortScience 35:230-34.

Francki, R.I.B. 1985. Plant virus satellites. Annu. Rev. Microbiol. 39:151-74.

Francki, R.I.B., D.W. Mossop, and T. Hatta 1979. Cucumber mosaic virus. No. 213 (No. 1 revised) in CMI/AAB descriptions of plant viruses. Commonwealth. Mycol. Inst., Assoc. Appl. Biol., Kew, Surrey, U.K. p. 1-5.

Garcia-Arenal, F., M. Zaitlin, and P. Palukaitis. 1987. Nucleotide sequence analysis of six satellite RNAs of cucumber mosaic virus: Primary sequence and secondary structure alterations do not correlate with differences in pathogenicity. Virology 158:339-347.

Habili, N. and J.M. Kaper 1981. Cucumber mosaic virus-associated RNA 5: VII. Double-stranded form accumulation and disease attenuation in tobacco. Virology 112:250-261.

Hidaka, S., K. Hanada, K. Ishikawa, and K. Miura. 1988. Complete nucleotide sequence of two new satellite RNAs associated with cucumber mosaic virus. Virology 164: 326-333.

Hidaka, S., K. Ishikawa, Y. Takanami, S. Kubo, and K.I. Miura. 1984. Complete nucleotide sequence of RNA 5 from cucumber mosaic virus (strain Y). FEBS Lett. 174:38-42.

Holland, J., K. Spindler, F. Horodyski, E. Grabau, S. Nichol, and S. VandePol. 1982. Rapid evolution of RNA genomes. Science 215:15771585.

Jordan, R.L., J.A. Dodds, and H.D. Ohr. 1983. Evidence for virus-like agents in avacado. Phytopathology 73:1130-1135.

Kaper, J.M., M.E. Tousignant, and M.T. Steen. 1988. Cucumber mosaic virus-associated RNA 5. XI. Comparison of 14 CARNA-5 variants relates ability to induce tomato necrosis to a conserved nucleotide sequence. Virology 163:284-292.
Kristensen, H.R. 1956. Virus diseases of cucumber in Denmark. Horticultura 10:161-172.

Kurath, G. and P. Palukaitis. 1987. Biological activity of T7 transcripts of a prototype clone and a sequence variant clone of a satellite RNA of cucumber mosaic virus. Virology 159:199-208.

Lot, J.M., J. Marrou, J.B, Quiot, and C. Esvan. 1972. Contribution a l'etude du virus de la mosaique du concombre (CMV). Ann. Phytopathol. 4:25-38.

Morris, T.J. and J.A. Dodds. 1979. Isolation and analysis of double stranded RNA from virus-infected plant and fungal tissue. Phytopathology 69:854-858.

Owen, J. and P. Palukaitis. 1988. Characterization of cucumber mosaic virus I. Molecular heterogeneity mapping of RNA 3 in eight CMV strains. Virology 166:495-502.

Provvidenti, R. 1976. Reaction of Phaseolus and Macroptilum species to a strain of cucumber mosaic virus. Plant Dis. Rptr. 60:289-293.

Roossinck, M.J. and P. Palukaitis. 1991. Differential replication in zucchini squash of a cucumber mosaic virus satellite RNA maps to RNA 1 of the helper virus. Virology 181:371-373.

Roossinck, M.J., D. Sleat, and P. Palukaitis. 1992. Satellite RNAs of plant viruses: Structures and biological effects. Microbiol. Rev. 56:265279.

Sambrook, J., E.F. Frisch and T. Maniatis. 1989. Molecular cloning: A laboratory manual. Cold Spring Harbor Lab. Press, Cold Spring Harbor, N.Y.

Schroeder, W.T. and R. Provvidenti. 1972. Alfalfa mosaic virus in Ajuga reptans. Plant Dis. Rptr. 56:285.

Shukla, D.D. and K.H. Gough. 1983. Tobacco streak, broad bean wilt, cucumber mosaic, and alfalfa mosaic viruses associated with ring spot of Ajuga reptans in Australia. Plant Dis. 67:221-23.

Sleat, D.E. and P. Palukaitis. 1990. Site-directed mutagenesis of a plant viral satellite RNA changes its phenotype from ameliorative to necrogenic. Proc. Natl. Acad. Sci. USA 87:2946-2950.

Sleat, D.E. and P. Palukaitis. 1990a. Induction of tobacco chlorosis by certain cucumber mosaic virus satellite RNAs is specific to subgroup II helper strains. Virology 176:292-295.

Sleat, D.E. and P. Palukaitis. 1992. A single nucleotide change within a plant virus satellite RNA alters the host specificity of disease induction. The Plant J. 2:43-49.

Steinhauer, D.A. and J.J. Holland. 1987. Rapid evolution of RNA viruses. Annu. Rev. Microbiol. 41:409-433.

Valverde, R.A., S.T. Nameth, and R.L. Jordan. 1990. Analysis of doublestranded RNA for plant virus diagnosis. Plant Dis. 74:255-258.

White, J.L. and J.M. Kaper.1987. Absence of lethal stem necrosis in select Lycopersicon spp. infected by cucumber mosaic virus strain D and its necrogenic satellite CARNA5. Phytopathology 77:808-811.

Zaitlin, M. and H.W. Israel. 1975. Tobacco mosaic virus (type strain). No. 151 in CMI/AAB Descriptions of plant viruses. Commonwealth Mycol. Inst., Assoc. Appl. Biol., Kew, Surrey, U.K. 